\title{
Violência institucional e enfermidade mental: narrativas de egressos de um manicômio da Bahia
}

\author{
Institutional violence and mental illness: narratives on people who \\ left a Brazilian psychiatric hospital
}

Antonio José Costa Cardoso', Gabriela Andrade da Silva1, Renê Luís Moura Antunes', Jaqueline Leu Santos ${ }^{\mathbf{1}}$, Daniela Viana da Silva1, Samuel Martins de Jesus Branco', Enrique Araujo Bessoni²

DOI: $10.1590 / 0103-1104202012712$

RESUMO Sob a perspectiva da Reforma Psiquiátrica, a presente pesquisa objetivou apresentar relatos de violência institucional em internações de longa duração em um manicômio a partir de itinerários de vida de pessoas em processo de desinstitucionalização. Foi realizada observação participante de nove beneficiários do Programa De Volta para Casa desospitalizados há 13 anos em município de grande porte da Bahia. Os diários de campo, assim como transcrições de entrevistas semiestruturadas com três profissionais de saúde, foram transformados em nove narrativas, que, analisadas qualitativamente, permitiram identificar violências sofridas no período anterior à admissão no hospital e da internação. As razões de internação diferiram por gênero: homens foram internados por crimes contra a pessoa; mulheres, por 'quebra de resguardo', frustrações amorosas e violência física e sexual. Durante a internação, emergiram o cotidiano administrado e a exposição à violência institucional (ausência de atividades socioterapêuticas, medicação em doses punitivas com efeito sedativo, negligência à saúde física, agressão física, confinamento, 'injeção' e 'choque elétrico', preconceito, estigma), em que os sujeitos tiveram neutralizadas suas possibilidades de reação à dominação. Os resultados proporcionaram reflexão sobre a violência do Estado, crucial no atual contexto de desconstrução da Política Nacional de Saúde Mental.

PALAVRAS-CHAVE Exposição à violência. Violência. Desinstitucionalização. Política pública. Hospitais psiquiátricos.

1 Universidade Federal do Sul da Bahia (UFSB) Itabuna (BA), Brasil. antoniojccardoso@gmail. com

2 Universidade Federal de São Paulo (Unifesp) - São Paulo (SP), Brasil.
ABSTRACT Under the perspective of the Psychiatric Reform, the aim of this article is to present reports of institutional violence in long-term psychiatric hospitalizations, based on the life itineraries of people in the process of deinstitutionalization in a large municipality in the state of Bahia, Brazil. We carried out participating observation including nine beneficiaries of the 'De Volta para Casa' ('Back Home') Program, who left the hospital thirteen years ago; and three semi-structured interviews with workers who assisted them. The researchers' field diaries and the interviews transcripts were transformed into narratives, which were analyzed qualitatively, in order to identify violence suffered before admission or during hospitalization. Reasons for hospitalization differed by gender: men were hospitalized for crimes against people; women, for 'breaking seclusion', love frustrations, physical and sexual violence. Contents about the administered daily life, and exposure to institutional violence (absence of socio-therapeutic activities, medication in punitive doses with sedative effect, neglect concerning physical health, physical aggression, confinement, 'injection', 'electric shock', prejudice, stigma), emerged from the reports about the hospitalization period, showing that the subjects had their possibilities of reacting against domination neutralized. The results provided reflection on State violence, crucial in the current context of deconstruction of the Brazilian Mental Health Policy.

KEYWORDS Exposure to violence. Violence. Deinstitutionalization. Public policy. Hospitals, psychiatric. 


\section{Introdução}

O presente trabalho apresenta um recorte dos resultados de uma pesquisa realizada com pessoas em processo de desinstitucionalização psiquiátrica que recebem o benefício do Programa De Volta para Casa (PVC) desde a sua implantação, em 20041,2. Embora tal pesquisa tenha objetivado avaliar o $\mathrm{PVC}$, as observações participantes e as entrevistas em profundidade realizadas durante o projeto trouxeram conteúdos profusos, que abarcam outras questões valiosas no âmbito da saúde mental; entre elas, os itinerários de vida dos participantes, que relataram histórias marcadas por diversos tipos de violências. Mesmo que a opressão de pessoas consideradas 'loucas' não seja uma novidade, dada a ampla literatura e discussões políticas a esse respeito ${ }^{3-5}$, o assunto permanece relevante, uma vez que ainda não há consenso quanto à imperativa necessidade de encerrarem-se as instituições asilares que alegadamente prestam assistência à saúde mental.

Por exemplo, um marcante retrocesso na política de saúde mental foi a publicação da Portaria GM/MS n ${ }^{0} 3.588$, de 21 de dezembro de 2017, na contramão do movimento de Reforma Psiquiátrica e mostrando a força política dos grupos conservadores. Essa portaria previu o hospital psiquiátrico especializado como dispositivo da Rede de Atenção Psicossocial (Raps), permitindo internações consideradas de curta permanência, com até 90 dias, e de longa permanência, com mais de 90 dias $^{6}$. Assim, considera-se fundamental ampliar as evidências que apoiem a discussão sobre a violência institucional característica de instituições asilares. Dessa forma, o objetivo do presente trabalho é apresentar relatos de violência institucional sofridos em internações de longa duração em um manicômio do estado da Bahia, a partir dos itinerários de vida de pessoas que estão em processo de desinstitucionalização e recebem o auxílio-reabilitação psicossocial do PVC.

$\mathrm{O}$ artigo está organizado em quatro seções além desta breve Introdução e das Considerações finais: Referencial teórico, que apresenta breve histórico e alguns marcos de referência da Reforma Psiquiátrica Brasileira (RPB), os mesmos deste estudo; Material e métodos, que apresenta a metodologia da pesquisa multiterritorial e multimétodos realizada em 11 cidades que sofreram intervenção do Ministério da Saúde em 2004, incluídos 2 municípios de grande porte do estado da Bahia, um dos quais foi a base para o presente artigo; e Resultados e discussão, organizada segundo o conceito de "carreira moral do doente mental", usado por Goffman ${ }^{7}$ para se referir à trajetória percorrida por uma pessoa que se torna interna de algum hospital psiquiátrico, com foco em duas fases: o período anterior à admissão no hospital, que ele denomina "fase de pré-paciente", e o período da internação no hospital, "fase de interno".

\section{Referencial teórico}

A relação entre instituições de assistência psiquiátrica e violência é tão antiga quanto a própria psiquiatria. Desde a criação, em Paris, da primeira instituição de natureza especificamente psiquiátrica por Pinel, existe questionamento quanto à violência impetrada pelo confinamento do louco ${ }^{3}$.

No Brasil, embora a fundação do Hospício D. Pedro II, no Rio de Janeiro, em 1852, possa ser tomada como marco institucional da assistência psiquiátrica a palavra de ordem 'aos loucos, o hospício!', lançada pela recém-criada Sociedade de Medicina e Cirurgia em 1830, sugere "a precedência da criação de instituições destinadas especificamente para abrigar loucos sobre o nascimento da psiquiatria"8.

Durante o Segundo Reinado (1840-1889), foram criadas instituições que se denominavam 'exclusivas para alienados' em São Paulo (1852), Pernambuco (1864), Pará (1873), Bahia (1874), Rio Grande do Sul (1884) e Ceará (1886), mas somente no início do século XX os médicos conseguiram desmontar as administrações leigas e as ordens religiosas que prestavam serviços nas Santas Casas ${ }^{3}$. 
Oda e Dalgarrondo 4 destacam que há claras indicações da existência de pressão para o confinamento do louco, garantindo que ele não ficasse perambulando pela rua à vista dos passantes, e da existência de uma opinião pública consensual quanto à necessidade $\mathrm{e}$ legitimidade de sua reclusão em hospícios ${ }^{3}$.

Com o advento da República, "os hospícios e as colônias agrícolas, destinadas aos loucos curáveis, [...] foram surgindo e se multiplicando pelos principais centros urbanos do país como ícones de sua modernização" ${ }^{5}$, mas o tratamento psiquiátrico continuou a ter como principal fundamento o isolamento do louco.

As décadas de 1940 e 1950 se caracterizaram pela expansão de hospitais psiquiátricos públicos propiciada pela aprovação do Decreto-Lei $\mathrm{n}^{0} 8.555 / 1946$. Naquela época, foram introduzidos o choque cardiazólico, a psicocirurgia, a insulinoterapia e a eletroconvulsoterapia ${ }^{3,9}$.

No bojo da construção dos direitos humanos como valor, o asilo passou a ser problematizado em vários países. No Brasil, ao contrário, observou-se uma expansão da rede de hospitais psiquiátricos privados a partir do golpe militar de $1964^{3}$. Foram os governos militares que consolidaram a privatização da assistência psiquiátrica com a contratação de leitos em hospitais privados ('indústria da loucura'), que saltou de 14 mil para 30 mil entre 1965 e 197010.

As internações passaram a ser feitas não apenas em hospitais públicos, que permaneceram reservados ao 'doente mental indigente', mas em instituições privadas, para os trabalhadores e seus dependentes ${ }^{3}$. E como o sistema de saúde mental e a mentalidade vigentes se organizaram em torno da internação prolongada e, na psiquiatria, ao contrário de outras especialidades médicas, os critérios diagnósticos e para prescrição do tratamento e internação nem sempre são claros ou indiscutíveis, o recurso a medidas de violação de direitos humanos para manter a obediência tornou-se a regra. Em verdade, usando o termo do glossário construído por Almeida-Filho"11, a loucura, para além de uma 'doença' (que pressupõe alterações morfofisiológicas e/ou funcionais), havia se tornado uma 'enfermidade', entendida em seu sentido etimológico que remete a encerrar, aprisionar (em francês: fermer, fechar), o que se relaciona com as primeiras medidas de controle de doenças infectocontagiosas por meio do isolamento.

Hospitais psiquiátricos seguem, até a atualidade, como instituições de enclausuramento destinadas às pessoas "consideradas incapazes de cuidar de si mesmas e que são também uma ameaça à comunidade, embora de maneira não-intencional"7(17). São "instituições totais" nos termos propostos por Goffman”:

um local de residência e trabalho onde um grande número de indivíduos com situação semelhante, separados da sociedade mais ampla por considerável período de tempo, levam uma vida fechada e formalmente administrada7(11).

Nos manicômios, o confinamento, os métodos disciplinares coercitivos, o uso excessivo de medicação e outros recursos de violação de direitos humanos para manter a obediência implicam a anulação das possibilidades de reação do interno ${ }^{12}$. No Brasil, a violência associada ao cuidado em hospitais psiquiátricos e judiciários - agressão, estupro, trabalho escravo, maus-tratos, tortura e mortes não esclarecidas - só seria denunciada a partir da segunda metade da década de 1970 no processo de 'abertura democrática'3,9,10.

Em 1990, a Declaração de Caracas ${ }^{\mathbf{1 3}}$ definiu princípios para a Reforma Psiquiátrica nas Américas: respeito à dignidade e aos direitos humanos e civis das pessoas com transtornos mentais; reconhecimento da Atenção Primária à Saúde como espaço privilegiado para a garantia da atenção integral; revisão do papel do hospital psiquiátrico e valorização de serviços de base comunitária; e práticas assistenciais promotoras da autonomia e permanência da pessoa portadora de transtornos mentais em seu meio.

Inspirada em diversas experiências de superação do asilo que ocorreram no continente europeu e nos Estados Unidos da América no pós-guerra e fundada na crítica ao saber 
psiquiátrico e ao modelo de cuidados centrado no hospital, a Política Nacional de Saúde Mental pretendeu avançar na direção proposta pela Declaração de Caracas. Uma das influências presentes é o trabalho de Franco Basaglia, que liderou o Movimento da Psiquiatria Democrática Italiana e influenciou a RPB.

Aprovada em 2001, a Lei $n^{0} 10.216$ (Lei da Reforma Psiquiátrica) ${ }^{\mathbf{1 4}}$ definiu a extinção progressiva dos hospitais psiquiátricos e sua substituição por uma rede de recursos assistenciais extra-hospitalares e regulamentou os direitos da pessoa com transtornos mentais seguindo a tendência dos direitos de terceira e quarta geração.

A Reforma Psiquiátrica pode ser compreendida como conjunto de iniciativas políticas, sociais e culturais, administrativas e jurídicas que busca transformar a instituição e o saber médico-psiquiátrico, mas também as práticas sociais, abrangendo não só o campo assistencial como também o conceitual, cultural e político, em que vêm sendo operadas várias transformações. O objetivo é possibilitar a construção de novas formas de convivência e transformar as tradicionais concepções de periculosidade, erro e desvio associadas à loucura. Além disso, a Reforma Psiquiátrica promove uma reestruturação das instituições ao possibilitar uma nova forma de pensar a loucura e ao promover serviços abertos de base comunitária ${ }^{15}$.

Entre 2000 e 2015, o processo de desinstitucionalização de pessoas longamente internadas foi impulsionado pela expansão dos Centros de Atenção Psicossocial (Caps), que passaram a receber uma linha específica de financiamento e se tornaram estratégicos para a organização da Porta de Entrada e regulação da rede; pela criação dos Serviços Residenciais Terapêuticos (SRT), casas inseridas na comunidade para egressos de internações de longa permanência em hospitais psiquiátricos e de custódia que não possuam alternativas de inserção social; e do PVC, que assegurou o pagamento mensal de um auxílio-reabilitação a essas pessoas.

Um marco na implantação da rede substitutiva aos hospitais psiquiátricos no Sistema Único de Saúde (SUS) foi a Portaria $\mathrm{n}^{\mathrm{0}} 3.088$, de 23 de dezembro de 2011, que instituiu a Raps para pessoas com sofrimento ou transtorno mental e com necessidades decorrentes do uso de crack, álcool e outras drogas ${ }^{16}$. Tal norma previu serviços articulados nos três níveis de atenção à saúde, além de novos serviços, tendo sido seguida por portarias que garantiram que a redução de leitos em hospitais psiquiátricos seria acompanhada de maiores investimentos na rede substitutiva.

No entanto, essa direção foi revista, em 2017, a partir da publicação da Portaria GM/MS $\mathrm{n}^{\mathrm{o}} 3588$, que previu o Hospital Psiquiátrico Especializado como dispositivo da Raps, possibilitando internações de curta e longa permanência ${ }^{6}$. Conforme explica a Nota Técnica $n^{0} 11 / 2019$, o Ministério da Saúde deixou de incentivar o fechamento dessas instituições, passando a estimular a qualificação da assistência. Portanto, paradoxalmente, afirma-se que o "processo de desinstitucionalização deva avançar, no entanto sem que seja excludente em relação à qualificação dos Hospitais Psiquiátricos remanescentes para oferta de vagas para internação a pacientes com quadros clínicos agudizados"17(24); mas, na prática, as internações longas ou mesmo perpétuas passaram a ser readmitidas no SUS.

\section{Material e métodos}

Com o objetivo de avaliar o impacto do PVC na desinstitucionalização e reintegração social dos beneficiários, foi realizada pesquisa multiterritorial e multimétodos em 11 cidades que sofreram intervenção do Ministério da Saúde em 2004, entre as quais 2 municípios de grande porte do estado da Bahia ${ }^{1}$. Na presente pesquisa, fez-se um recorte, apresentando dados baseados em um desses municípios.

Selecionaram-se os dez beneficiários mais antigos do PVC residentes no município. Destes, apenas um se recusou a assinar o Termo de Consentimento Livre e Esclarecido 
(TCLE). A pesquisa contou, então, com a participação de nove beneficiários, todos egressos da mesma instituição psiquiátrica. Também participaram três pessoas que faziam parte da gestão do PVC e da equipe de assistência aos beneficiários.

O trabalho de campo foi realizado entre 11 de setembro e 23 de outubro de 2017. Foi implantado um Comitê de Acompanhamento de Pesquisa (CAP) ${ }^{18}$ com a participação de gestores, profissionais de saúde, cuidadores, usuários e pesquisadores, cujas reuniões foram gravadas e transcritas. O CAP se reuniu duas vezes, uma ao início e outra ao final do campo, para devolutiva.

Dois pesquisadores foram responsáveis por realizar 13 visitas para observação participante nos 5 SRT em que os participantes moravam. As observações participantes foram norteadas por linha-guia produzida conjuntamente por pesquisadores da equipe nacional de pesquisa, procurando articular as atividades de campo com o marco teórico da investigação. Nas visitas, procurou-se construir um vínculo com os participantes, que permitiu uma convivência profícua, com compartilhamento de acontecimentos de vida cotidiana e, muitas vezes, do convite para conhecer e participar de suas vidas: almoçar na residência, dançar, ver fotos antigas, conhecer os dormitórios e os pertences, por exemplo. Dessas vivências, foi possível apreender o cotidiano presente, bem como adentrar em relatos que retomaram os acontecimentos do passado e as aspirações e desejos para o futuro. Considerou-se que a gravação dessas atividades poderia intimidar os participantes e reduzir a espontaneidade nos encontros; por isso, as visitas para fins de entrevistas e observação participante foram registradas em diários de campo após as percorridas.

As atividades de campo também envolveram entrevistas semiestruturadas, audiogravadas, com duas gestoras da Secretaria Municipal de Saúde e com o gestor de um dos Caps do município, que era referência para parte dos SRT em que moravam beneficiários do PVC participantes desta pesquisa. Essas entrevistas buscaram esclarecer aspectos do histórico de implantação do PVC, da gestão atual dos recursos e do acompanhamento e cuidado aos beneficiários do PVC.

Os diários de campo e as transcrições de entrevistas e reuniões do CAP subsidiaram a construção de nove narrativas, uma por participante. A metodologia de construção das narrativas foi detalhada em artigo publicado pela equipe nacional ${ }^{19}$. Em síntese, versões iniciais foram elaboradas pelas equipes locais de pesquisa, buscando contemplar quatro dimensões definidas a priori: trajetória de vida; autonomia versus opressão; o que o dinheiro do PVC faz poder; acesso à saúde, acesso à vida. Posteriormente, os textos foram trocados entre os pesquisadores de diferentes campos e debatidos, buscando-se registros mais ricos e levantamento das diversas possibilidades de contar as histórias dos beneficiários.

Neste artigo, as narrativas foram analisadas visando descrever a 'carreira moral de doente mental' (usando o termo empregado por Goffman) e compreender a violência a que foram submetidos os ex-internos. Embora cada entrevista se refira a um sujeito singular, elementos recorrentes foram agrupados, buscando compreender as vivências dos ex-internos, com foco nas formas de violência a que estiveram expostos.

A pesquisa foi analisada pelo Comitê de Ética em Pesquisa da Fiocruz Brasília pelo CAAE 57627316.4.0000.8027 e aprovada sob o Parecer 1.699.082. Foram adotados procedimentos para o consentimento livre e esclarecido dos participantes; e, para evitar a sua identificação, o presente artigo apresenta nomes fictícios e omite dados pessoais.

\section{Resultados e discussão}

Esta seção está organizada segundo o conceito de "carreira moral do doente mental", usado por Goffman ${ }^{7}$ para se referir à trajetória percorrida por uma pessoa que se torna interna de algum hospital psiquiátrico, com foco na sequência de mudanças que a internação provoca em sua 
identidade. O perfil dessas pessoas pode variar quanto ao tipo e gravidade da enfermidade mental, mas, uma vez iniciados nessa carreira, enfrentarão circunstâncias semelhantes que não decorrerão de sua enfermidade.

Todos os participantes da pesquisa recebiam o auxílio-reabilitação do PVC e, embora não tenha sido planejado no delineamento desta pesquisa, todos residiam em SRT na época da coleta de dados. Dos nove ex-internos entrevistados, seis são mulheres (Camila, Márcia, Gilmara, Dora, Margarida e Valentina) e três são homens (José, Antonio e Manoel), com idade variando de 46 a 76 anos.

Segundo Goffman", a "carreira moral do doente mental" se estrutura em três fases: $o$ período anterior à admissão no hospital, que ele denomina "fase de pré-paciente"; o período da internação no hospital, "fase de interno"; e o período que sucede a alta no hospital, quando ocorreria a "fase de ex-interno". Este artigo refere-se às duas primeiras.

\section{Vivências da fase de pré-paciente: violência doméstica enas ruas}

As análises das narrativas da fase de 'pré-paciente' (quadro 1) mostraram importantes diferenças por gênero. Entre homens, associando (Antonio) ou não (Manoel) o abuso de álcool à enfermidade mental, o crime contra a pessoa foi o principal motivo da internação, mas houve também o relato de José, que sofreu a tragédia de uma desestruturação familiar: oriundo de uma família que "possuía bens", seu pai "perdeu tudo com amantes".

Quadro 1. Síntese das narrativas relatando histórico de vida na fase pré-paciente

\begin{tabular}{|c|c|}
\hline Participante & Síntese da narrativa \\
\hline Antonio & $\begin{array}{l}\text { Antonio "bebia desde a infância", foi internado por alcoolismo em um hospital na capital do estado, onde foi abandonado por seus } \\
\text { pais ainda criança. Nunca compreendeu o motivo de sua internação em um segundo hospital psiquiátrico, ocorrida exatamente } \\
\text { quando acabara de conseguir um emprego como vigia de um polo petroquímico. Segundo funcionária do Caps, "depois que cometeu } \\
\text { um crime, a família considerou que ele estava louco e o internou". }\end{array}$ \\
\hline Manoel & $\begin{array}{l}\text { Tendo chegado no município "de caminhão", Manoel não sabe sua procedência, seu local de nascimento, quem o trouxe ou quantos } \\
\text { anos tinha na época. Sabe que tem família, mas perdeu o contato com todos. Recorda-se de sua irmã, de plantar abóbora e melancia } \\
\text { em um roçado e de um rio com muitos peixes, onde costumava pescar de anzol. Não lembra a razão de ter ido morar no hospital } \\
\text { psiquiátrico, mas, segundo a cuidadora, o motivo foi o estupro da irmã, com quem teria tido um filho. Por isso, a família o internou no } \\
\text { hospital e "não quis mais nem ouvir falar dele". }\end{array}$ \\
\hline José & $\begin{array}{l}\text { José pouco falou sobre seu percurso antes de ingressar no manicômio. Segundo sua cuidadora, ele sofreu a tragédia de uma deses- } \\
\text { truturação familiar: oriundo de uma família que "possuía bens", seu pai "perdeu tudo com amantes". }\end{array}$ \\
\hline Dora & $\begin{array}{l}\text { Natural de outra cidade baiana, Dora foi levada pelo seu irmão mais velho para morar com sua madrinha no município onde agora se } \\
\text { encontra, tendo estudado até o terceiro ano do magistério. Interrompeu os estudos antes de começar a dar aulas, mas trabalhou em } \\
\text { estabelecimentos comerciais como vendedora. Dora teve um filho, que, segundo ela, tem } 26 \text { anos e cujo pai seria um funcionário de } \\
\text { uma conhecida empresa da área de energia. Conta que, quando veio morar no município atual, nunca imaginou ir para o manicômio, } \\
\text { mas confidenciou-nos, em tom de sussurro, que foi para o hospital por conta de um estupro. Disse que foram marginais, que isso } \\
\text { aconteceu na rua. De acordo com a cuidadora, o estupro foi cometido na cidade de origem de Dora, por dois ou três homens que } \\
\text { bateram nela e a ameaçaram com um revólver. Seu filho seria fruto desse estupro. }\end{array}$ \\
\hline Margarida & $\begin{array}{l}\text { Segundo Margarida, seus pais tiveram três filhos antes dela: um menino, falecido de "doença do umbigo", e duas meninas, uma das quais é } \\
\text { moradora de outra Residência Terapêutica. Margarida foi criada na roça, sua mãe faleceu quando ela tinha um ano. Após a morte do pai, por } \\
\text { "beber cachaça" e por "feitiçaria de uma filha de santo", ficou morando na estrada, numa "casinha de sapé" à "beira de uma mata virgem", onde } \\
\text { ajudava a tomar conta de uma roça de café. Frequentou por pouco tempo duas escolas, mas não aprendeu a ler. Morava com uma tia mater- } \\
\text { na quando se mudou para uma cidade grande "para cuidar de uma menina". Certo dia, resolveu fugir. Deixou a chave na "casa do bispo" e saiu } \\
\text { caminhando. Foi encontrada pela polícia, que a levou de volta. Tornou a fugir. Dessa vez, a encontraram "caminhando sem rumo" e a levaram } \\
\text { para o manicômio. Após três meses, voltou para a roça, onde engravidou. Durante a gravidez, ela se queixou à sogra que estava sentindo } \\
\text { dores, mas a sogra respondia que "mulher grávida é assim mesmo". Então, resolveu ir embora. Caminhou sem rumo até outra cidade, onde sua } \\
\text { filha nasceu. Nesse período, um rapaz "se aproveitou" dela, resultando em "peito estourado", o que a obrigou a dar a menina. Tempos depois, } \\
\text { tentou reaver a bebê, mas o casal para quem entregou sua filha lhe fez a "injúria" de dizer que ela nunca havia deixado criança alguma aos } \\
\text { seus cuidados. Segundo Margarida, o motivo da sua reinternacão foi porque "saía caminhando à toa". }\end{array}$ \\
\hline
\end{tabular}


Quadro 1. (cont.)

\begin{tabular}{|c|c|}
\hline Participante & Síntese da narrativa \\
\hline Valentina & $\begin{array}{l}\text { Natural de um município pequeno, Valentina trabalhou em casa de família, lavava pratos e limpava a casa. Teve um filho, Ivan, fruto } \\
\text { de relacionamento com um "policial bonito". Ela acredita que tenha enlouquecido por causa do parto, por "resguardo quebrado", mas } \\
\text { Ivan é "do tempo em que ela era sã", de acordo com a cuidadora. Lembra que chegou no manicômio "em 1994" porque estava "apron- } \\
\text { tando" em sua cidade de origem, ficou doente e a prenderam em uma "cela". O "delegado assinou no prontuário" e os funcionários do } \\
\text { hospital a encaminharam para o manicômio. }\end{array}$ \\
\hline Márcia & $\begin{array}{l}\text { Nascida em família humilde, Márcia morava com sua mãe e nove irmãos em uma cidade grande. Não estudou - "minha mãe não me } \\
\text { colocou na escola" - e não sabe ler nem escrever, mas sempre foi uma mulher ativa, trabalhou em casas de família lavando roupa e } \\
\text { fazendo de tudo, "com exceção do almoço". Vendia produtos de limpeza na rua com sua mãe, mas o dinheiro, sua mãe "pegava e gas- } \\
\text { tava". Depois de algum tempo, ela e seus irmãos foram expulsos de casa. Márcia engravidou de um homem ciumento que a espan- } \\
\text { cava muito, inclusive com pontapés na barriga, o que provocou um abortamento. Em outro relacionamento, engravidou de Lucas, } \\
\text { que nasceu em um município próximo a Salvador. Após o nascimento de Lucas, ela foi expulsa de casa com o seu filho nos braços. } \\
\text { Passou a morar nas ruas e, devido ao frio e às chuvas, a criança "pegou pneumonia". O juiz "tomou" Lucas, que ficou sob os cuidados } \\
\text { de uma freira. Márcia voltou às ruas, "subindo e descendo com a manta nos braços, com os seios vazando leite, caminhando e chorando". } \\
\text { Ela acredita que teve "resguardo quebrado". Não lembra a idade que tinha quando isso aconteceu porque ficou esquecida desde então. }\end{array}$ \\
\hline Gilmara & $\begin{array}{l}\text { Natural do município onde se deu a internação, Gil possui familiares próximos. De acordo com a cuidadora, foram "problemas de } \\
\text { casamento" que a levaram à loucura e à consequente internação no manicômio. Segundo Luciana, a cuidadora, Gil se recusou a se } \\
\text { casar com Marcus, pretendente apoiado por sua avó; em vez disso, envolveu-se com outro rapaz, Miguel, do qual engravidou e teve } \\
\text { um filho. Miguel queria se casar com Gil, mas ela não aceitou, porque gostava de Rubens, que não quis ficar com ela. }\end{array}$ \\
\hline Camila & $\begin{array}{l}\text { Natural do município onde se deu a internação, Camila se mudou, ainda criança, para uma cidade a } 360 \text { Km de lá, quando foi ado- } \\
\text { tada por uma família conhecida por sua influência política nesse segundo município. Sua mãe adotiva tinha dois filhos biológicos. } \\
\text { Camila gostava de onde morava e recorda-se do endereço de sua casa, de ruas e avenidas importantes, de um rio que percorre } \\
\text { grande parte da cidade, do trajeto para chegar na igreja católica aonde ia. Camila cursou magistério, tendo trabalhado como profes- } \\
\text { sora primária em um colégio estadual durante dois anos. Religiosa, frequentava igrejas, mas também festas de forró e praias, pois } \\
\text { sua família possuía uma casa em município litorâneo. Aos } 17 \text { anos, o seu curso de vida foi alterado pelo falecimento dos seus pais } \\
\text { adotivos, quando seus irmãos a internaram no hospital psiquiátrico, alegando "doença mental". Depois da internação, Camila foi } \\
\text { interditada, sem direito a herança, e seus irmãos nunca mais foram vê-la. }\end{array}$ \\
\hline
\end{tabular}

Fonte: Elaboração própria.

Para as mulheres, violência sexual (Dora e Margarida), "resguardo quebrado" (Valentina e Márcia) e "frustrações amorosas" (Gilmara) aparecem como eventos disruptivos associados às internações, configurando um padrão completamente diferente daquele observado entre os homens. No caso de Dora, Margarida e Márcia, o gatilho para a loucura se relaciona com um episódio de violência física e sexual. Márcia, por exemplo, relatou várias experiências de violência: o homem que a raptou para um local escuro e tentou enforcá-la; o ex-namorado que lhe chutou a barriga até causar um aborto; o outro que lhe ameaçou quebrar os braços e as pernas. Hoje, diz que não quer saber de homens, ao menos não para namorar.

Consideradas mães "loucas", Márcia, Valentina, Dora e Margarida foram, além disso, desligadas de maneira traumática de seus filhos e internadas no hospital psiquiátrico. A trajetória de Márcia envolveu abandono da família (mãe), violência física e sexual em decorrência de relações de gênero desiguais, violações de direitos trabalhistas (deveria ter estabilidade no emprego após o nascimento do filho), privação do direito aos vínculos familiares (perda da guarda do filho) e violação de seus direitos reprodutivos, ao submetê-la contra a sua vontade a uma cirurgia de esterilização que lhe tirou a possibilidade de vivenciar a maternidade e que ocorreu por meio da união de forças do poder judiciário (Juiz), da igreja católica (freira que providenciou a adoção de seu filho) e da medicina (médica que fez sua laqueadura sem consentimento).

Márcia não se esqueceu dessas violências. As feridas ainda sangram. O tempo não empregado na criação ou convívio com seu filho 
parece ser uma perda irrecuperável. Restalhe, atualmente, vivenciar a função materna de forma simbólica, ao cuidar de suas filhas bonecas, ou nem tanto, ao cuidar de Pedro, outro morador do SRT. Se pessoas desconhecidas adotaram seu filho Lucas, ela adotou Pedro, que "é assim" porque a família "judiou" e "abandonou". Supõe-se que, ao cuidar do amigo, ela também cuida de si mesma por transferência, encontrando alívio para suas próprias dores.

Márcia disse várias vezes que não é louca, mas que adoeceu por conta do "resguardo quebrado". Isso despertou curiosidade para saber que significados essa expressão assume: a quebra de resguardo seria referente às proibições do puerpério imediato, como atividade sexual? Teriam Márcia e Valentina sofrido de psicose pós-parto? É importante lembrar que, na Bahia, o termo "quebrar o resguardo" também costuma ser aplicado ao descumprimento de obrigações rituais de religiões de matriz afro-brasileira.

O relato de Camila destoou das demais participantes. Adotada por uma família rica, foi internada pelos irmãos após o falecimento dos pais adotivos. Em verdade, o motivo de sua internação não teria sido um transtorno mental, mas um jogo de interesses financeiros decorrentes de herança. Esse relato reafirma o papel do manicômio enquanto instituição de controle, cuja finalidade terapêutica encobre outros interesses ${ }^{7,20}$.

Ainda em dias atuais, as interdições civis permanecem articulando o sistema de justiça com o imaginário social da periculosidade e incapacidade do louco. Essa forma mitigada e invisível de dominação e violência sobre o sujeito, que lança mão de um dispositivo legal destinado à proteção do incapaz, isto é, sua curatela, tornou-se um procedimento repetido pelas varas de família, apoiadas em pareceres do campo da saúde mental21.

O perfil dos ex-internos é semelhante ao perfil dos usuários dos serviços públicos de saúde mental geral22-24. Grande parte dos participantes são pessoas que, além do sofrimento mental, sofreram com violências de vários tipos: baixa renda ou pobreza - que envolve falta de moradia ou moradia precária, baixa escolaridade, emprego precário ou desemprego -, abandono familiar e abuso de álcool, preconceito, estigma etc. Nesse sentido, os problemas sociais parecem até mais evidentes do que a enfermidade mental.

As narrativas de Margarida, que "saía caminhando à toa"; de Valentina, que estava "aprontando" em sua cidade; e de Márcia, que voltou às ruas, "subindo e descendo com a manta nos braços, com os seios vazando leite, caminhando e chorando", exemplificam bem o caso das pessoas com enfermidade mental que, vivendo nas ruas, dormindo ao relento, eram recolhidas por policiais que as levavam para os hospitais psiquiátricos ${ }^{25}$, reafirmando o papel do manicômio como local de controle e depósito de personagens indesejados pela sociedade ${ }^{20}$.

\section{Vivências da fase de interno: violência interpares e institucional}

O hospital psiquiátrico é o local em que mais se expressa a violência sobre as pessoas com enfermidades mentais. Seja no momento da internação compulsória ou involuntária, seja pelas características asilares dessas instituições, seja ainda pela ausência de poder de contratualidade, de direitos humanos e cidadania das pessoas consideradas loucas, o 'interno' é alguém que perde a autonomia, perde a voz ${ }^{26}$.

A vida em hospitais psiquiátricos e em manicômios consiste em um transcorrer restrito a um espaço geográfico limitado, na companhia de um aglomerado de pessoas que, excluídas do convívio familiar, do trabalho e do local em que moram, são submetidas a uma terapêutica de massa e conduzidas a realizar atividades em horários preestabelecidos, atendendo-se a rotinas institucionais ${ }^{27}$.

O hospital de onde egressaram os participantes desta pesquisa foi criado na década de 1960, recebendo internos de outros hospitais, pretensamente com a missão de promover 'atividades socioterapêuticas', tendo chegado 
a ter 900 internos na década de 2000. Uma cuidadora, que conheceu o hospital à época, conta que "aquilo não era digno para nenhum ser humano viver. Era deprimente". Os internos sofriam violência física, "andavam presos igual a bicho, recebendo comida por debaixo da porta" e "havia boatos de que mulheres eram estupradas por vigilantes".

Embora incluído no Programa Anual de Reestruturação da Assistência Hospitalar Psiquiátrica no SUS, o fechamento do hospital não foi efetivado, mas passou-se a trabalhar para a redução progressiva dos leitos, e Projetos Terapêuticos Individuais foram elaborados no intuito de iniciar a desospitalização. Apesar do investimento na desinstitucionalização, o hospital ainda está em funcionamento e contava com cerca de 80 pacientes crônicos quando encerrou-se a fase de campo desta pesquisa, os quais, alegadamente, ainda não puderam ser desospitalizados em função do grau de incapacidade e dependência da instituição. $\mathrm{O}$ trabalho de desinstitucionalização continua.
Os nove participantes desta pesquisa relataram suas vivências desse período de institucionalização, aqui organizadas em três blocos: primeiro, o registro descritivo dos elementos que definiam suas vidas como formalmente administradas; depois, as duras memórias da violência institucional; e, por fim, a construção dos laços de amizade e relacionamentos românticos, bem como a participação nas atividades festivas promovidas pela instituição, que definiram como "a parte boa da vida no hospital".

Quanto aos elementos que definiam suas vidas administradas, as narrativas (quadro 2) destacaram a falta de autonomia na condução de suas vidas, a obrigatoriedade do uso de farda ("homens com uniformes azuis e mulheres com uniformes cor de rosa"), a realização de refeições, banho e outras atividades rotineiras em horários preestabelecidos, a impossibilidade de escolher companheiros ou companheiras de quarto e o sistema de vigilância (controle do acesso por meio de portões, portarias e guardas).

Quadro 2. Síntese das narrativas relatando o cotidiano controlado durante a fase de interno

\begin{tabular}{|c|c|}
\hline Participante & Síntese da narrativa \\
\hline José & José não sabe dizer quanto tempo ficou internado, mas afirma que foram "muitos anos". \\
\hline Manoel & $\begin{array}{l}\text { Manoel não saber dizer ao certo por quanto tempo ficou internado no manicômio, mas diz que foi por "muito tempo". Homens e } \\
\text { mulheres moravam separados em espaços conhecidos como módulos. Em um total de quatro, eram divididos em dois ou três quar- } \\
\text { tos. Manoel vivia no Módulo I. Somente nas refeições, realizadas em espaço comum, pessoas de ambos os gêneros se encontravam. } \\
\text { Relatou que vivia medicado e dormia grande parte do tempo. }\end{array}$ \\
\hline Antonio & $\begin{array}{l}\text { Tendo chegado ao manicômio em 1982, Antonio "deitava e rolava", "esculhambava", saía, passava a noite fora e, quando voltava, dizia } \\
\text { que estava na rua passeando. Antonio "era orientado", comprava e vendia coisas, fazia de tudo: "tinha uma roça, era carroceiro, tinha } \\
\text { três carroças, tinha até uma plantação de maracujá". Ele acordava às cinco da manhã para colher os maracujás antes que o "pessoal do } \\
\text { [nome do bairro]" roubasse, mas bebia, fumava e namorava muito. Segundo ele, sua vida era de bar em bar, onde gastava o dinheiro. }\end{array}$ \\
\hline Camila & $\begin{array}{l}\text { Embora não se lembre de tudo da época da internação, recorda-se que o hospital era dividido por módulos e que cada módulo tinha } \\
\text { de dois a três quartos. Nos módulos } 1 \text { e } 2 \text {, moravam os homens (com uniformes azuis); e, nos módulos } 3 \text { e } 4 \text {, as mulheres (com uni- } \\
\text { formes cor de rosa). Camila morou no módulo } 3 \text {. Embora morassem em módulos separados, o almoço para homens e mulheres era } \\
\text { servido no mesmo refeitório. A rotina limitava-se a levantar para comer, tomar banho e tomar remédios que a faziam dormir muito, o } \\
\text { que levou a uma perda da noção do tempo durante o período que viveu no hospital. Recorda-se que havia muita gente, alguns mais } \\
\text { "deficientes" do que outros, muitos acamados, e que outros tantos morreram. }\end{array}$ \\
\hline Márcia & $\begin{array}{l}\text { Descreveu os "vestidos de pacientes" (fardas usadas pelas internas) como feios, ressaltando que não se considerava "doida" para usar aquela } \\
\text { roupa. Não havia nada bom, somente "doidos". Márcia recorda que ela não dormia nem se alimentava direito, tendo emagrecido "a ponto de } \\
\text { precisar tomar soro". }\end{array}$ \\
\hline Dora & $\begin{array}{l}\text { Conta que o hospital tinha uma área muito grande e que ela ajudava a lavar o refeitório e as mesas. Comentou que eles usavam fardas, sendo } \\
\text { a das mulheres um vestido rosa. Ela dividia o quarto com três companheiras. }\end{array}$ \\
\hline
\end{tabular}


Quadro 2. (cont.)

\begin{tabular}{ll}
\hline Participante & Síntese da narrativa \\
\hline Margarida & Conta que morava "uma multidão de gente" e que todos vestiam fardas da cor azul ou rosa. A cor rosa era para "as pacientes", e ela usava um \\
& "vestidinho". Recorda que ficou "muito tempo". \\
Valentina & Valentina nos contou que não faziam nada, ficavam na cantina, só faziam comer e dormir, mas que a comida era boa. O problema, entretan- \\
& to, é que ela ficava presa e "separada de Yuri" (companheiro amoroso, com quem morou depois da desinternação), pois a área dos homens \\
& era separada da área das mulheres. Foi no manicômio que conheceu Yuri e onde conviveram por dez anos. Valentina usava o cabelo curto e \\
& "farda" - não gostava da farda. Mas gostava do hospital, porque namorava e conversava com "os pacientes". Contou sobre outros namorados \\
& que teve.
\end{tabular}

A desassistência se manifestava na ausência de atividades socioterapêuticas e na supermedicalização (tratamento padronizado e doses punitivas, com efeito sedativo). Camila contou que não sabe quanto tempo ficou internada, porque "lá eu tomava remédio, dormia, só acordava mesmo para tomar banho, pra tomar café, pra almoçar e tomar remédio. Aí eu dormia muito, então eu não sei”.

Observou-se também a falta de cuidados com a saúde física dos usuários, como se pôde perceber em falas de gestores e profissionais da Raps. Em reunião do CAP, relataram casos de pessoas que chegaram ao SRT com problemas de saúde física cronificados. Por exemplo, uma usuária com prolapso uterino, relatado por uma profissional da Raps: "por que essa pessoa estava no [nome do hospital] há tantos anos com esse problema e veio para a residência terapêutica assim? E nunca operou?".

Essa negligência no cuidado à saúde é reveladora de um senso comum permissivo ao desrespeito à dignidade das pessoas que sofrem de transtornos mentais. Ademais, embora não tenha sido relatado pelos próprios usuários, as cuidadoras das Residências Terapêuticas (RT) e profissionais de saúde da Raps confidenciaram que, ao egressar do hospital, alguns ex-internos ainda mantinham comportamentos adquiridos durante o período de institucionalização, como ficar sem roupas, defecar ou urinar em público e fora do vaso sanitário, traduzindo a desassistência a que estiveram submetidos.

Em geral, tais comportamentos eram relatados pelas cuidadoras, segundo as quais, na primeira RT em que morou,

Antonio ajudava a orientar os demais residentes a tomar banho, dava o café a eles, fazia cuscuz para todos e limpava o chão da residência quando um residente defecava.

Camila, quando chegou à RT, ficava "nua enrolada no lençol"; Dora "pegava a comida e colocava no lixo, e só depois é que ela ia comer. Não vestia calcinhas, pois ela as jogava fora e vivia nua dentro de casa".

Quanto às memórias de alguma violência intencional praticada pela equipe dirigente, conforme quadro 3, os ex-internos relacionaram o recurso à agressão física, ao confinamento, à "injeção" e ao "choque elétrico" como estratégias de punição utilizadas quando "as pessoas [estavam] mais agitadas e agressivas". Mesmo que esses relatos se refiram às internações anteriores, em outros hospitais psiquiátricos, sinalizam o padrão a que eram submetidos.

Lá [no manicômio] ela ficava presa, mas nunca apanhou, nem levou choque. As pessoas que davam choque eram as do [...] [nome de outro hospital psiquiátrico].

Antonio, referindo-se aos tempos em que morou nesse outro hospital, disse: "quase tomei [eletrochoque] uma vez porque brigava com os outros por causa de ponta de cigarro, mas consegui correr". 
Quadro 3. Síntese das narrativas relatando memórias de violência institucional na fase de interno

\begin{tabular}{ll}
\hline Participante & Síntese da narrativa \\
\hline Camila & $\begin{array}{l}\text { Para as pessoas mais agitadas e agressivas, havia uma "solitária"; e, em casos mais extremos, as enfermeiras administravam uma } \\
\text { "injeção". }\end{array}$ \\
Márcia & $\begin{array}{l}\text { Passou por cirurgia de esterilização sem consentimento. Conta que as enfermeiras deixavam os internos sem o café da manhã quan- } \\
\text { do eles se atrasavam por estarem, supostamente, "namorando nas celas". }\end{array}$ \\
Dora & Dora tomava muitos medicamentos, mas só davam choque elétrico em quem não se comportava bem. \\
Margarida & $\begin{array}{l}\text { Sobre a sua vida no manicômio, Margarida nos conta que, como sabiam que ela trabalhava como doméstica, a colocavam para } \\
\text { trabalhar na cozinha pela manhã e à tarde, onde lavava pratos, fazia faxina, areava panelas. }\end{array}$ \\
Valentina & Sua cama era de cimento, "parecendo sarjeta", e o colchão, fino. Tinha muita muriçoca. Nunca apanhou nem levou choque. \\
Manoel & $\begin{array}{l}\text { Relatou ter feito amigos de quem gosta muito, mas "foi um período em que judiaram muito de mim"; não apanhava, mas vivia medicado e dor- } \\
\text { mia grande parte do tempo. }\end{array}$ \\
& $\begin{array}{l}\text { De acordo com Antonio, foi no hospital que ele sofreu o acidente que Ihe deixou no corpo duas protuberâncias, bastante visíveis, na } \\
\text { cabeça e nas costas. Nesse acidente, ele teve a cabeça aberta e uma perfuração no olho direito. Passou por um procedimento que } \\
\text { durou mais de duas horas, e a única coisa que pediu ao médico foi para não perder a visão. Não ficou cego. }\end{array}$ \\
\hline
\end{tabular}

Relataram também formas mais sutis de violência: "as enfermeiras deixavam os internos sem o café da manhã quando eles se atrasavam, diziam que por estarem namorando nas celas" e "colocavam para trabalhar na cozinha pela manhã è à tarde, onde lavava pratos, fazia faxina, areava panelas" quem eles "sabiam que [...] [a interna] trabalhava como doméstica", por exemplo.

Também houve a queixa de Valentina de que a "cama era de cimento, parecendo sarjeta, e o colchão, fino"; e foi narrado um episódio de grave acidente ocorrido com Antonio, com sequelas permanentes.

Nesse acidente, ele teve a cabeça aberta e uma perfuração no olho direito. Tendo chegado ao pronto-socorro às treze horas, somente foi atendido às duas horas da manhã. Coberto de sangue, como ninguém Ihe atendia, Antonio quebrou tudo. Passou por um procedimento no olho que durou mais de duas horas e a única coisa que pediu ao médico foi para não perder a visão. Não ficou cego.

A violência também se manifestava na perda do direito de preservar relações interpessoais. Os ex-internos se ressentem dos vínculos rompidos com a família, colegas de trabalho e amigos (pois as visitas eram inexistentes ou raras). No caso de filhos menores de idade, nascidos anteriormente ou durante a internação, tudo indica a perda do poder familiar, com encaminhamento das crianças para adoção - muitas vezes, pelos próprios funcionários do hospital - e completa separação. Alguns usuários nunca mais tiveram contato com os filhos e manifestam o desejo de reencontrá-los, mas apenas em raros casos obteve-se sucesso nessas reaproximações, mesmo quando os filhos foram localizados.

Todas as vezes em que houve visita a Márcia, foram frequentes seus pedidos para que seu filho, que ficou aos cuidados de uma freira, fosse encontrado. Ela disse que "reza todas as noites pedindo para reencontrar o filho e imagina que já tenha nora e netos". Antonio tem nove filhos, quatro nascidos durante sua internação no hospital psiquiátrico, mas

os médicos tomaram e não deixaram que ele tivesse qualquer contato. Um deles foi adotado por um certo Dr. Joaquim, esse já está grande, mas também não tem contato com ele. Ele não lembra os nomes das mães, porém sabe que uma delas mora em uma RT. 
O filho de Gilmara mora com sua família e ela já foi visitá-lo, levando presentes, mas o rapaz, com 16 anos, não quis se aproximar da mãe. Valentina também não tem mais contato com o filho que teve antes da internação.

Talvez para compensar, foram relatadas experiências positivas vivenciadas durante a internação (quadro 4), sobretudo em datas comemorativas - São João, Natal, Micareta -, mas também o futebol e a horta. Essas atividades podem ajudar o indivíduo a suportar a tensão psicológica usualmente criada pelos ataques ao eu e, juntamente com os laços de amizade e relacionamentos românticos, foram apontadas como a parte boa da vida no hospital. Por meio do processo de confraternização, o grupo dos internos se uniu, desenvolveu apoio mútuo e cumplicidade ${ }^{28}$.

No entanto, são justamente as referências constantes que os participantes fizeram a essas comemorações que reafirmam o caráter do hospital enquanto instituição total, que pode ser vista como uma espécie de mar morto, em que aparecem pequenas ilhas de atividades vivas e atraentes. É precisamente na insuficiência de tais atividades que se pode encontrar um importante efeito de privação das instituições totais ${ }^{7}$.

Quadro 4. Síntese das narrativas relatando memórias de experiências consideradas positivas ("a parte boa") na fase de interno

\begin{tabular}{ll}
\hline Participante & Síntese da narrativa \\
\hline Camila & Camila recorda-se que fez muitos amigos por lá. Durante sua internação, participou de um bloco de carnaval do próprio hospital, que \\
& saía pelas ruas na micareta da cidade. Contou das festas de São João e de Natal. \\
Márcia & Dos relacionamentos amorosos que teve no hospital, Márcia destacou Gabriel, que "era bonito", e Daniel, que "era aposentado" e lhe \\
& presenteava - embora tenha dito que ele ameaçou quebrar seus braços e pernas e, por isso, terminou o relacionamento. \\
Dora & Participava das festas como o Mabelão e do bloco de carnaval. Chora porque, segundo ela, a família não a quer e, embora diga que \\
& gosta de morar na RT, pede para voltar para o hospital. \\
Margarida & Margarida gostava do manicômio e tinha amigos lá, inclusive funcionários. Conta que todos a tratavam bem e que havia um homem \\
& que comprava as bonecas que ela fazia. Era "um monte de boneca feita com panos de retalhos". \\
Valentina & Valentina nos contou que gostava do manicômio porque namorava e conversava com "os pacientes". Contou sobre outros namorados que \\
& teve. Todo ano tinha Natal e São João. Gostava do São João, pois dançava forró e quadrilha. Havia filmagens e ensaio. Na micareta, saía no \\
& bloco de carnaval, que tinha abadá e fantasia. \\
José & No manicômio, conheceu Maria, por ele descrita como uma "mulher bonita", que namorou; conheceu também Ana, com quem viveu "ama- \\
& siado", e Antonio, com quem mora atualmente. José foi "amasiado" com Ana por um longo período no manicômio e permaneceram juntos na \\
& RT até o seu falecimento. \\
& Relatou ter feito amigos de quem gosta muito, mas "foi um período em que judiaram muito de mim"; não apanhava, mas vivia medicado \\
& e dormia grande parte do tempo. \\
Manoel & Durante o período no Colônia, Antonio "deitava e rolava", "esculhambava", saía, passava a noite fora e, quando voltava, dizia que es- \\
& tava na rua passeando. Durante as micaretas, saía à noite e só voltava no dia seguinte. Sua vida era de bar em bar, onde gastava o \\
& dinheiro. Antonio parou de beber aos 51 anos, quando frequentou o Alcoólicos Anônimos por um ano.
\end{tabular}

\section{Considerações finais}

A violência associada à produção do sofrimento psíquico em contextos institucionais em que os sujeitos tiveram neutralizadas suas possibilidades de reação à dominação, como é o caso do confinamento em hospitais psiquiátricos e de custódia (manicômios judiciários), traz à reflexão a violência do Estado. Esta reflexão é uma contribuição dos autores à luta em defesa dos direitos das pessoas portadoras de transtornos mentais no atual contexto de desconstrução da Política Nacional de Saúde Mental. 
Segundo Adorno,

a visibilidade da violência na sociedade contemporânea destaca-se a partir de duas esferas de construção de significados: a violência do Estado, violência política, e a violência privada ou no âmbito da família24(4).

A primeira, inclusive aquela associada ao confinamento em hospitais psiquiátricos, remete à construção dos direitos humanos como valor; a segunda "desponta a partir dos movimentos sociais, sobretudo o movimento feminista"29(4).

As narrativas foram analisadas visando descrever a 'carreira moral de doente mental' e compreender a violência a que foram submetidos os ex-internos, utilizando-se conceitos e marcos teóricos de referência coerentes das obras de Foucault, Goffman, Basaglia. As memórias dos sujeitos emergiram como lembranças de aspectos objetivos e subjetivos, muitas vezes incoerentes e conflitantes, mas que possibilitaram a análise da violência no período anterior à admissão e no período da internação.

Na fase de pré-paciente, o crime contra a pessoa, associando ou não o abuso de álcool à enfermidade mental, foi o principal motivo da internação entre os homens; no caso das mulheres, violência sexual, 'resguardo quebrado' e 'frustrações amorosas' aparecem como eventos disruptivos associados às internações, configurando um padrão diferente, mas os problemas sociais (baixa renda ou pobreza, que envolve falta de moradia ou moradia precária, baixa escolaridade, emprego precário ou desemprego, abandono familiar e abuso de álcool) parecem mais evidentes do que a enfermidade mental.

$\mathrm{Na}$ fase de interno, a análise das narrativas permitiu recuperar o cotidiano administrado (falta de autonomia na condução de suas vidas, obrigatoriedade do uso de farda, realização de atividades rotineiras em horários preestabelecidos, impossibilidade de escolher companheiros ou companheiras de quarto, sistema de vigilância e vínculos rompidos com a família, colegas de trabalho e amigos) e mapear as formas de violência institucional a que estiveram expostos (ausência de atividades socioterapêuticas, tratamento padronizado e doses punitivas com efeito sedativo, mas também negligência no cuidado à saúde física dos usuários, agressão física, confinamento, 'injeção' e 'choque elétrico', além de preconceito, estigma).

Tais resultados revelam um senso comum permissivo ao desrespeito à dignidade das pessoas que sofrem de transtornos mentais e a banalização da violência em contextos institucionais em que os sujeitos tiveram neutralizadas suas possibilidades de reação à dominação. No contexto político brasileiro contemporâneo, são constatações que merecem ser trazidas à reflexão, na medida em que se observa o gradativo retorno da lógica manicomial, conforme as novas orientações da Política Nacional de Saúde Mental5,17.

\section{Colaboradores}

Cardoso AJC (0000-0002-6085-3502)* e Silva GA (0000-0002-4188-0935)* contribuíram igualmente para a elaboração do manuscrito com as seguintes atividades: 1) coordenação local da pesquisa; 2) concepção e o planejamento do artigo; 2) elaboração do primeiro manuscrito do artigo; 3) análise e interpretação dos dados; 4) revisão crítica do conteúdo e versão final do manuscrito. Antunes RLM (0000-0002-8106-1352)* e Santos JL (00000001-5527-6715)* contribuíram igualmente para a elaboração do manuscrito com as seguintes atividades: 1) análise e interpretação dos dados; 2) revisão crítica do conteúdo. Silva DV (00000002-1693-1374)* e Branco SMJ (0000-00033486-3560)* contribuíram igualmente para a elaboração do manuscrito com as seguintes atividades: 1) coleta de dados na pesquisa de campo; 2) análise e interpretação dos dados; 3) revisão crítica do conteúdo. Bessoni EA (00000003-0521-1627)* contribuiu para a elaboração do manuscrito com as seguintes atividades: 1 ) coordenação nacional da pesquisa; 2) análise e interpretação dos dados; 3) revisão crítica do conteúdo e versão final do manuscrito.
* Orcid (Open Researcher and Contributor ID). 


\section{Referências}

1. Guerrero AVP, Bessoni EA, Cardoso AJC, et al. O Programa de Volta para Casa na vida cotidiana dos seus beneficiários. Saúde soc. 2019; 28(3):11-20.

2. Bessoni E, Capistrano A, Silva G, et al. Narrativas e sentidos do Programa de Volta para Casa: voltamos, e daí? Saude soc. 2019; 28(3):40-53.

3. Fonte EMM. Da institucionalização da loucura à reforma psiquiátrica: as sete vidas da agenda pública em saúde mental no Brasil. Estudos Soc. 2013; 1(18Sl).

4. Oda AMGR, Dalgarrondo P. História das primeiras instituições para alienados no Brasil. Hist Cienc Saude Manguinhos 2005; 12(3):983-1010.

5. Passos ICF. Loucura e sociedade: discursos, práticas e significações sociais. Belo Horizonte: Argvmentvm Editora; 2009.

6. Brasil. Ministério da Saúde, Gabinete do Ministro. Portaria $\mathrm{n}^{\circ} 3.588$, de 21 de dezembro de 2017. Altera as Portarias de Consolidação $n^{\circ} 3$ e $n^{\circ}$ 6, de 28 de setembro de 2017, para dispor sobre a Rede de Atenção Psicossocial, e dá outras providências. Diário Oficial da União [internet]. 22 Dez 2017. [acesso em 2019 abr 29]. Disponível em: http://pesquisa.in.gov.br/impren$\mathrm{sa} /$ jsp/visualiza/index.jsp?data $=22 / 12 / 2017$ \&jornal= $515 \&$ pagina $=236 \&$ totalArquivos $=416$.

7. Goffman E. Manicômios, prisões e conventos. São Paulo: Perspectiva; 1974. [acesso em 2021 fev 10]. Disponível em: https://app.uff.br/slab/uploads/Manicomios-prisoes-e-conventos.pdf.

8. Resende H. Política de saúde mental no Brasil: uma visão histórica. In: Tundis S, Costa N, organizadores. Cidadania e loucura: políticas de saúde mental no Brasil. Petrópolis: Vozes; 2007. p. 15-73.

9. Pacheco JG. Reforma psiquiátrica, uma realidade possível: representações sociais da loucura e a história de uma experiência. Curitiba: Juruá; 2009.

10. Tenório FA. Reforma psiquiátrica brasileira, da déca- da de 1980 aos dias atuais: história e conceitos. Hist Cienc Saude Manguinhos. 2002; 9(1):25-59.

11. Almeida-Filho NM. O que é saúde? Rio de Janeiro: Fiocruz; 2011.

12. Foucault M. O sujeito e o poder. In: Rabinow P, Dreyfus HL, Foucault M, organizadores. Uma trajetória filosófica para além do estruturalismo e da hermenêutica. Rio de Janeiro: Forense Universitária; 1995. p. 231-49.

13. Organização Pan-Americana da Saúde, Organização Mundial da Saúde. Declaração de Caracas. Caracas: OPAS; 1990.

14. Brasil. Lei $\mathrm{n}^{\circ} 10.216$, de 6 de abril de 2001. Dispõe sobre a proteção e os direitos das pessoas portadoras de transtornos mentais e redireciona o modelo assistencial em saúde mental. Diário Oficial da União [internet]. 9 Abr 2001. [acesso em 2019 ago 10]. Disponível em: http://www.planalto.gov.br/ccivil_03/ leis/leis_2001/110216.htm.

15. Salles MM, Barros S. Transformações na atenção em saúde mental e na vida cotidiana de usuários: do hospital psiquiátrico ao Centro de Atenção Psicossocial. Saúde debate. 2013; 37(97):324-335.

16. Brasil. Ministério da Saúde, Gabinete do Ministro. Portaria ${ }^{0} 3.088$, de 23 de dezembro de 2011. Institui a Rede de Atenção Psicossocial para pessoas com sofrimento ou transtorno mental e com necessidades decorrentes do uso de crack, álcool e outras drogas, no âmbito do Sistema Único de Saúde (SUS). Diário Oficial da União [internet]. 26 Dez 2011. [acesso em 2019 abr 29]. Disponível em: http://pesquisa.in.gov. br/imprensa/jsp/visualiza/index.jsp?data $=26 / 12 / 2$ 011\&jornal=1\&pagina=230\&totalArquivos $=320$.

17. Brasil. Ministério da Saúde, Secretaria de Atenção à Saúde. Nota Técnica no 11/2019. Esclarecimentos sobre as mudanças na Política Nacional de Saúde Mental e nas Diretrizes da Política Nacional sobre Drogas, 2019 [internet]. [acesso em 2021 jan 10]. 
Disponível em: https://pbpd.org.br/wp-content/ uploads/2019/02/0656ad6e.pdf.

18. Vaz BC, Lyra J, Cardoso AJC, et al. Produção compartilhada de conhecimentos em saúde mental: o comitê de acompanhamento de pesquisa. Saúde soc. 2019; 28(3):21-28.

19. Koosah J, Moreira MIB, Braga-Campos FC. Construindo histórias em tessitura lenta: desinstitucionalização e narrativas em pesquisa. Saúde e Soc. 2019; 28(3):29-39.

20. Foucault, M. História da loucura na idade clássica. São Paulo: Perspectiva; 1978.

21. Delgado PGG. Violência e saúde mental: os termos do debate. O Social em Questão. 2012; 15(28):187-198.

22. Barros S, Bichaff R, organizadores. Desafios para a desinstitucionalização: censo psicossocial dos moradores em hospitais psiquiátricos do Estado de São Paulo [internet]. São Paulo: FUNDAP; Secretaria da Saúde; 2008. [acesso em 2019 dez 16]. Disponível em: http://pfdc.pgr.mpf.mp.br/atuacao-e-conteudos-de-apoio/publicacoes/saude-mental/censo_psicossocialsP.pdf.

23. Oliveira EN, Silva MWP, Eloia SC, et al. Caracterização da clientela atendida em Centro de Atenção Psicossocial - Álcool e Drogas. Revista da Rede de Enfermagem do Nordeste. 2013; 14(4):748-756.

24. Trevisan ER, Castro SdS. Centros de Atenção Psicossocial - álcool e drogas: perfil dos usuários. Saúde debate. 2019; 43(121):450-463.
25. Sadigursky D, Tavares JL. Algumas considerações sobre o processo de desinstitucionalização. Rev. latinoam. Enfermagem. 1998; 6(2):23-27.

26. Amarante P, Ribeiro ND, Constantino P. Pessoas institucionalizadas e violência. In: Impactos da violência na saúde. Rio de Janeiro: Fiocruz; 2007. p. 223-245.

27. Bastos LC, Aguiar MGG. Vivências de moradores de residências terapêuticas de Feira de Santana, Bahia: do fio da vida administrada no "hospital colônia" à vida em liberdade na cidade. RBSP. 2011; 35(2):432445.

28. Benelli SJ. O internato escolar como instituição total: violência e subjetividade. Psicol. estud. [internet]. 2002 [acesso em 2021 jan 10]; 7(2):19-29. Disponível em: https://www.scielo.br/scielo.php?pid=S1413$-73722002000200004 \&$ script=sci_abstract\&tlng=pt.

29. Adorno RF. Uso de álcool e drogas e contextos sociais da violência. SMAD. Rev. Eletrônica Saúde Mental Álcool Drog [internet]. 2008 [acesso em 2021 jan 10]; 4(1). Disponível em: http://pepsic.bvsalud.org/scielo.php?script=sci_arttext\&pid $=$ S1806-69762008000100002.

Recebido em 30/03/2020

Aprovado em 19/08/2020

Conflito de interesses: inexistente

Suporte financeiro: Fundação de apoio à Fiocruz (Fiotec) e

Programa de Iniciação à Pesquisa, Criação e Inovação (PIPCI) da

Universidade Federal do Sul da Bahia 